\title{
Ionization, Plume Properties, and Performance of Cylindrical Hall Thrusters
}

\author{
Kevin D. Diamant, James E. Pollard, Yevgeny Raitses, and Nathaniel J. Fisch
}

\begin{abstract}
It is shown experimentally that the cylindrical Hall thruster (CHT) produces a highly ionized plasma flow with mass utilization efficiencies greater than $100 \%$ due to generation of multicharged ions. For the CHT employing geometries with and without a short annular section, used to enhance ionization, plume divergence reductions of approximately $25 \%$ were demonstrated by running a cathode-keeper discharge along with the main cathode-anode discharge. Thruster anode efficiencies varied from approximately $15 \%$ to $35 \%$ over input powers from 70 to $220 \mathrm{~W}$. A 2-A keeper discharge resulted in an approximately $20 \%$ increase in anode specific impulse for both geometries, and the specific impulse for the case of no annular section was, on average, $13 \%$ higher than that with the annular section. The multicharged ion fraction increased with keeper current, and the quantity of channel erosion products in the plume was correlated with that of multicharged ions.
\end{abstract}

Index Terms-Charge state, Hall thruster, ion flux, performance, plume.

\section{INTRODUCTION}

$\mathbf{T}$ HE CONCEPT of operationally responsive access to space is leading to increased interest in small low-power spacecraft [1]. These severely mass- and power-limited spacecraft could benefit from the use of low-power electric propulsion for orbit maintenance. Hall thrusters may be an attractive option due to their simplicity relative to ion thrusters and high performance relative to cold gas or electrothermal thrusters.

Annular Hall thrusters have been extensively developed in the power range from approximately 0.5 to $5 \mathrm{~kW}$, with specific impulses ranging typically from 1500 to $2000 \mathrm{~s}$ and total efficiencies from $45 \%$ to $55 \%$ (see, e.g., [2]-[6]). A number of methodologies are available for scaling Hall thrusters to power levels below a few hundred watts while attempting to preserve specific impulse and efficiency [7]-[12]. All face the same challenges, created by the need to reduce channel size in order to preserve ionization efficiency. Small size leads to difficulty in generation of magnetic fields with appropriate magnitude and topology and also to increased particle losses to chamber walls, with consequent increases in electron trans-

Manuscript received October 28, 2009; revised January 19, 2010. First published March 18, 2010; current version published April 9, 2010. This work was supported by The Aerospace Corporation's Independent Research and Development Program.

K. D. Diamant and J. E. Pollard are with The Aerospace Corporation, El Segundo, CA 90245-4691 USA (e-mail: kevin.d.diamant@aero.org; james.e.pollard@aero.org).

Y. Raitses and N. J. Fisch are with the Plasma Physics Laboratory, Princeton University, Princeton, NJ 08543 USA (e-mail: yraitses@pppl.gov; fisch@princeton.edu).

Color versions of one or more of the figures in this paper are available online at http://ieeexplore.iee.org.

Digital Object Identifier 10.1109/TPS.2010.2042623 port, heating, erosion, and plume divergence [13], [14] and, therefore, reduced efficiency, specific impulse, and life. With a few exceptions (BHT-200 [8], KM-37 [13], SPT X-40 [14], and SPT-20M6.1 [15]), anode efficiencies (i.e., thrust efficiency calculated without accounting for propellant flow to a cathode) for annular Hall thrusters operating below $200 \mathrm{~W}$ are less than $40 \%$.

Raitses et al. [16] developed a cylindrical Hall thruster (CHT), combining the conventional annular design with the simplicity and enhanced volume-to-surface-area ratio of the end-Hall thruster (EHT). The CHT channel features an annular region near the anode, followed by a cylindrical region. The annular region was designed to facilitate ionization, with acceleration occurring mainly in the cylindrical region, where there is no inner wall and, consequently, reduced particle losses [17], [18]. As with the EHT [19], the magnetic field has substantial axial as well as radial components, with a magnetic mirror in the central portion of the channel. However, in contrast to the EHT, plasma potential measurements in the CHT indicate that the magnetic field lines form equipotential surfaces [18]. In addition, the CHT channel is ceramic (boron nitride), while the EHT channel consists largely of the metallic anode [19]. The magnetic mirror in the CHT serves mainly to inhibit electrons from entering the annular part of the channel [20]. The CHT exhibits quiet operation [17] and high ionization efficiency [21]. A 3-cm-diameter CHT achieved anode efficiencies from $20 \%$ to $27 \%$ at input powers from 90 to $185 \mathrm{~W}$ [22]. More recently, it was found that, by "overrunning" the discharge current (i.e., running a cathode-keeper discharge in addition to the main discharge to the anode) in 2.6- and 3-cm-diameter CHTs, plume divergence was reduced by $20 \%-30 \%$ and that the ion energy distribution was shifted to higher energies [23]. Anode efficiencies of 33\%-41\% (not including power required to overrun the discharge) at $50-175 \mathrm{~W}$ were measured with the 2.6-cm thruster [23].

In this paper, we present measurements of plume narrowing and performance enhancement in the overrun current regime for a 3-cm CHT and for the same thruster with the annular portion removed (fully CHT or FCHT). The FCHT design was introduced by Raitses and Fisch [24], and a 5.6-cm-diameter version has been developed and studied by Shirasaki and Tahara [25]. We will also present data on ion charge state and erosion species in the plume.

\section{EXPERIMENT}

The 3-cm CHT (Fig. 1) has been described in detail elsewhere [23], [26]. The FCHT is the same thruster, modified so 


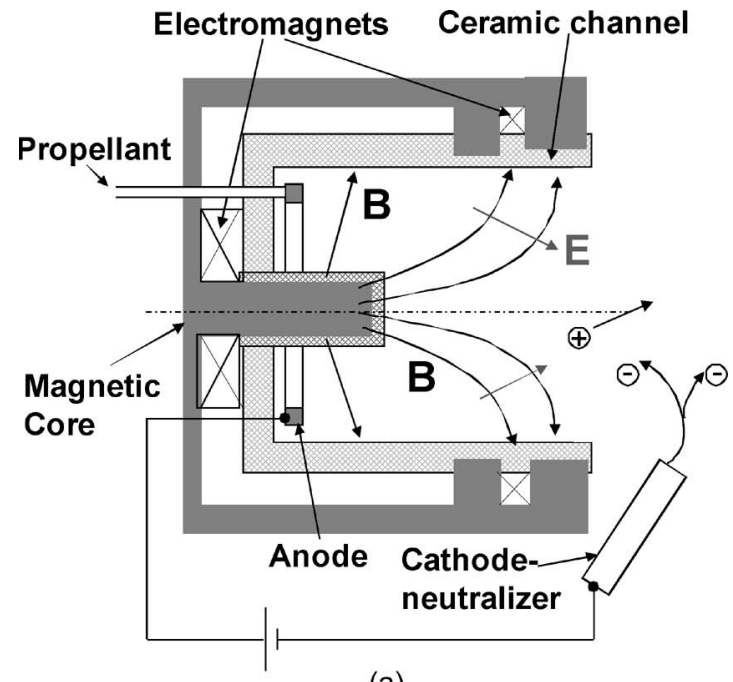

(a)

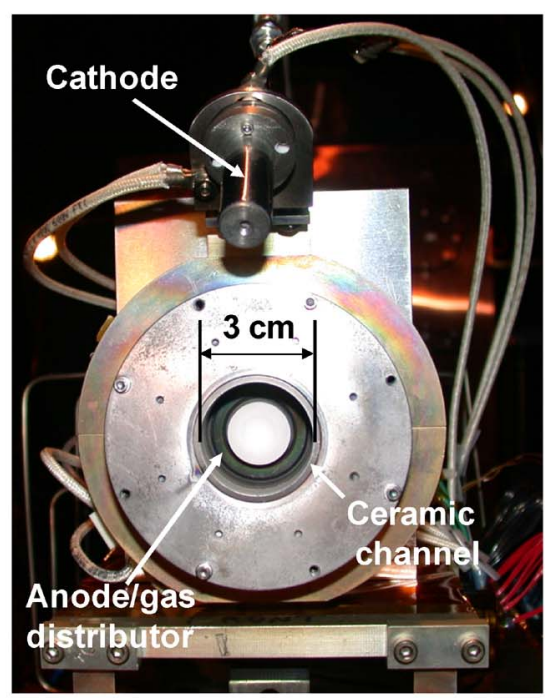

(b)

Fig. 1. (a) CHT schematic. (b) 3-cm CHT.

that the inner channel wall ends flush with the downstream face of the anode. In all cases, the two magnet coils were run in what Smirnov, Raitses, and Fisch refer to as the "direct" configuration, which produces an enhanced axial component of the magnetic field at the outer wall and a stronger magnetic mirror on the thruster axis [20]. Magnet currents were $2 \mathrm{~A}$ except as noted. A commercial hollow cathode (Heatwave Labs model HWPES-250) supplied electrons to the discharge and plume. This cathode consists of a hollow tube with a bariumimpregnated porous tungsten emitter, enclosed by a keeper electrode. As in [23], the overrun current regime was attained by running a keeper discharge in addition to the main discharge to the anode. The cathode-keeper exit aperture was located $54 \mathrm{~mm}$ radially from the thruster centerline and $20 \mathrm{~mm}$ downstream of the thruster exit plane. The angle between the thruster and cathode axes was approximately $40^{\circ}$. Xenon gas was supplied to the anode and cathode by thermal mass flow controllers, calibrated by timing the pressure rise in a $1-\mathrm{L}$ volume. The cathode flow rate was $0.2 \mathrm{mg} / \mathrm{s}$ in all cases. Testing occurred in a 2.4 -m-diameter $\times 9.8$-m-long cryopump vacuum chamber.

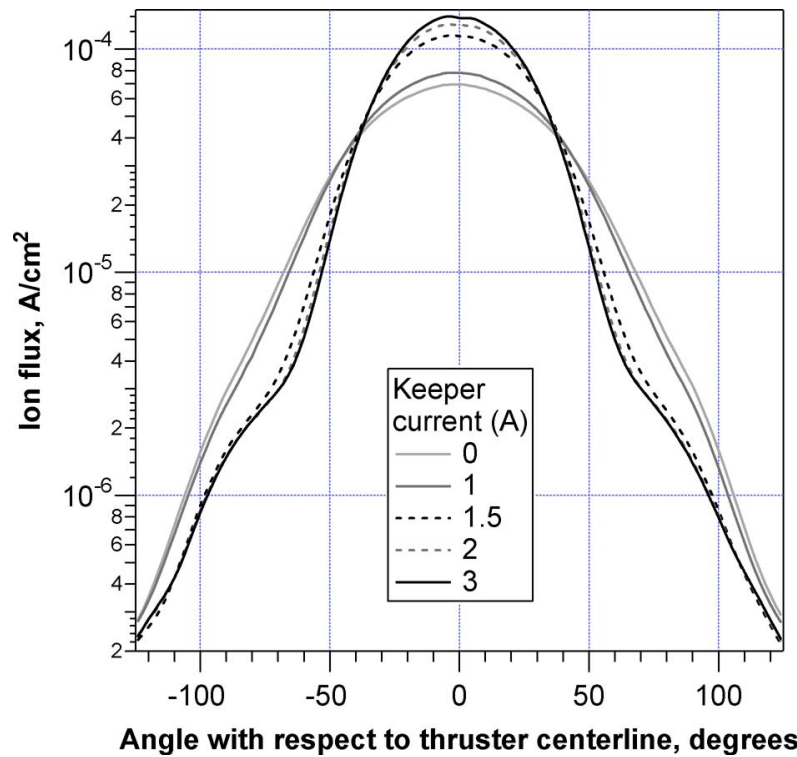

Fig. 2. CHT ion flux at $250 \mathrm{~V}, 0.40 \mathrm{mg} / \mathrm{s}$, and $50-\mathrm{cm}$ radius for various keeper currents.

During thruster operation at a total flow of $0.6 \mathrm{mg} / \mathrm{s}$, chamber pressure (corrected for xenon) was typically $9 \times 10^{-7}$ torr.

The thruster was mounted on an inverted-pendulum-style thrust stand, described in [27]. Ion flux was measured at $2^{\circ}$ increments at a radius of $50 \mathrm{~cm}$ from the thruster exit plane by a planar probe consisting of a $1.27-\mathrm{cm}$-diameter collector, surrounded by a $2.54-\mathrm{cm}$-outside-diameter 1.32 -cm-insidediameter guard ring. Collector and guard ring were stainless steel, and both were biased to $-20 \mathrm{~V}$ with respect to ground. Ion flux was integrated to determine the total beam current and plume divergence. Plume divergence is defined as the half angle containing $90 \%$ of the total ion current. The ion energy distribution with respect to ground was measured at $50-\mathrm{cm}$ radius with a retarding potential analyzer, described in [28]. Ion charge state and erosion products were detected, also at $50-\mathrm{cm}$ radius, with a compact time-of-flight spectrometer, described in [29].

Measurement uncertainties are estimated to be $\pm 1^{\circ}$ for plume divergence, $\pm 5 \%$ for specific impulse, and $\pm 10 \%$ for efficiency.

\section{RESUlts AND Discussion}

Fig. 2 shows the ion current density profiles at various keeper currents for the CHT at a main discharge voltage of $250 \mathrm{~V}$ and anode flow rate of $0.40 \mathrm{mg} / \mathrm{s}$ (discharge currents are typically $0.49,0.51$, and $0.53-0.54 \mathrm{~A}$ for keeper currents of $0-1,1.5$, and 2-3 A, respectively). Fig. 3 shows plume divergence for the CHT and FCHT at various operating points. These figures confirm the substantial plume narrowing reported in [23] for the CHT and demonstrate that the same effect is present in the FCHT. Plume divergence decreased from an average of $71^{\circ}$, with no keeper current, to $55^{\circ}$ at $2 \mathrm{~A}$ and $53^{\circ}$ at $3 \mathrm{~A}$. Fig. 4 shows that a keeper current of $2 \mathrm{~A}$ caused CHT primary ion peaks to shift to higher energies, and reduced the number of primary ions at high angles, in agreement with [23]. The ion energy shift was correlated with a shift in the cathode floating potential from about $12-14 \mathrm{~V}$ below ground to $1-3 \mathrm{~V}$ below ground, equivalent to roughly one-half to two-thirds of the ion 


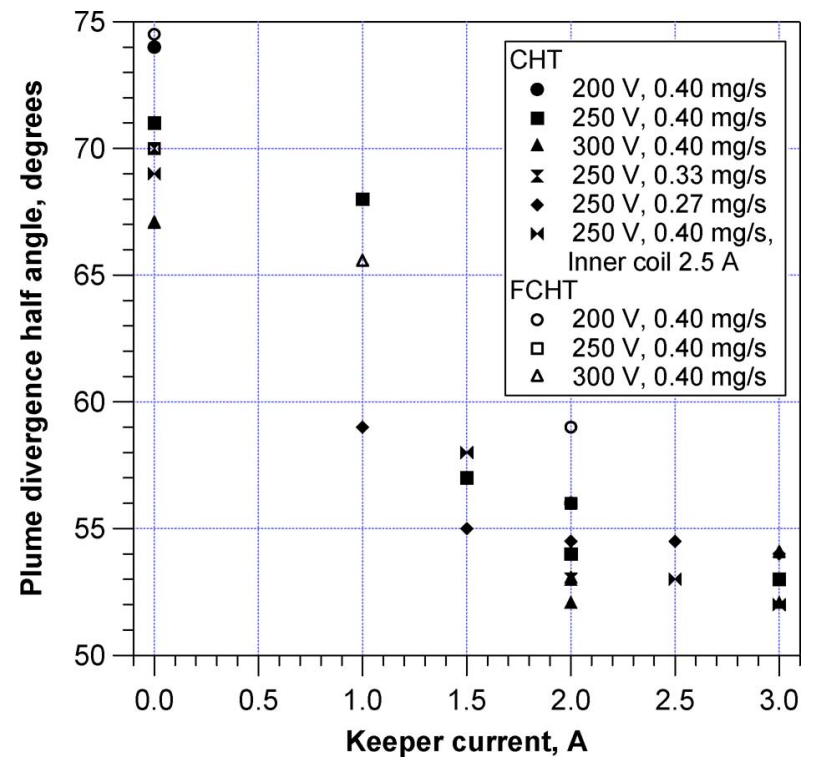

Fig. 3. Plume divergence.

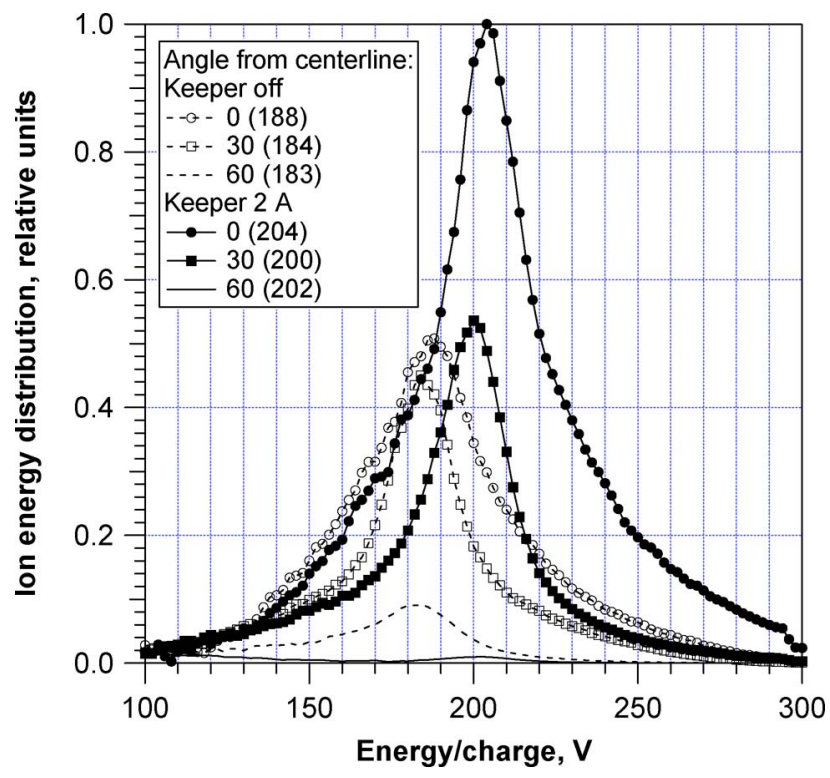

Fig. 4. CHT ion energy distribution at $50-\mathrm{cm}$ radius, $250 \mathrm{~V}$, and $0.40 \mathrm{mg} / \mathrm{s}$. Peak center voltages are listed in parentheses in the legend.

energy shift. Fig. 5 shows the CHT running with and without a keeper discharge of $2 \mathrm{~A}$. The keeper discharge affected the appearance of the plume (more conical) and caused the cathode to transition from plume mode to spot mode. The plumeto-spot-mode transition is associated primarily with increased plasma density inside the cathode [30] and reduced voltage between the cathode and the external electron collector [31], in this case the ion beam. This latter characteristic was evident in the aforementioned shift of cathode floating potential. An explanation for the correlation between cathode plasma density and the full ion energy shift, as well as plume narrowing, is not yet available. Granstedt et al. [32] used a hot filament cathode instead of a hollow cathode and showed that the CHT plume narrowing results from increasing the heating current to a filament cathode beyond that necessary to sustain the discharge, indicating that cathode electron emission capacity is the critical

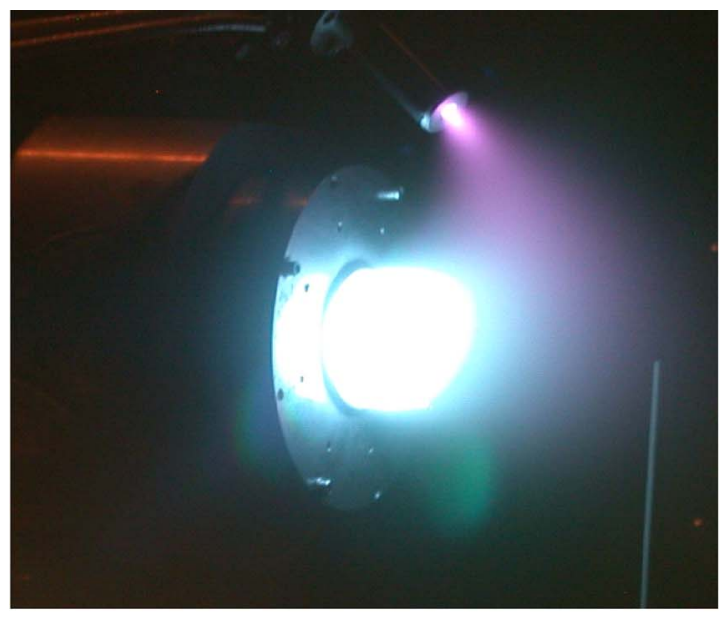

(a)

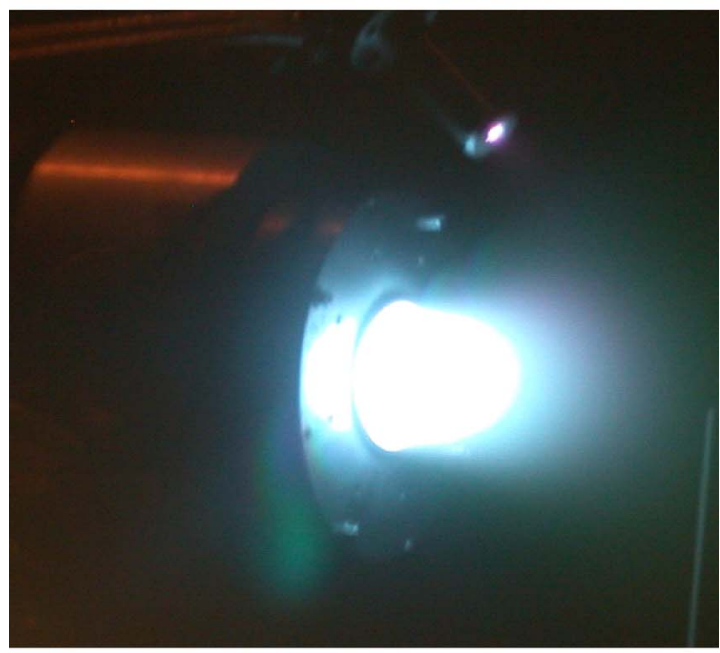

(b)

Fig. 5. CHT firing: $250 \mathrm{~V}$ and $0.40 \mathrm{mg} / \mathrm{s}$. (a) Keeper off. (b) Keeper 2 A.

factor. According to the study in [32], the shift of the ion energy distribution to higher energies with the keeper current is due to ion production in the plasma region at higher potential.

The CHT and FCHT have similar anode efficiencies (Fig. 6), and for both thrusters, with efficiency improvement created by the narrower, more energetic plume was offset by the power consumed by the keeper discharge (keeper voltage was typically $10-12 \mathrm{~V}$ at keeper currents from 1 to 3 A). Presumably, a cathode that is capable of generating adequate plasma density without a supplemental discharge would achieve the higher efficiencies shown by the open symbols in Fig. 6. Fig. 7 shows the benefit of the keeper discharge to CHT and FCHT anode specific impulse, with an average gain of $21 \%$ between 0 and 2 A. FCHT specific impulse was, on average, $13 \%$ higher than that of the CHT at keeper currents of 0 and $2 \mathrm{~A}$. The possibility of thrust generation by the cathode was investigated by running it alone with a 2-A keeper discharge. Cathode thrust was below the resolution of the thrust stand $(0.1 \mathrm{mN})$. Furthermore, the total ion current from the cathode was measured to be approximately $1 \%$ of the thruster beam current, and no ions were detected at energies above $20 \mathrm{~V}$, indicating that cathode thrust was on the order of $0.01 \mathrm{mN}$ (approximately $0.2 \%$ of typical CHT thrust). 


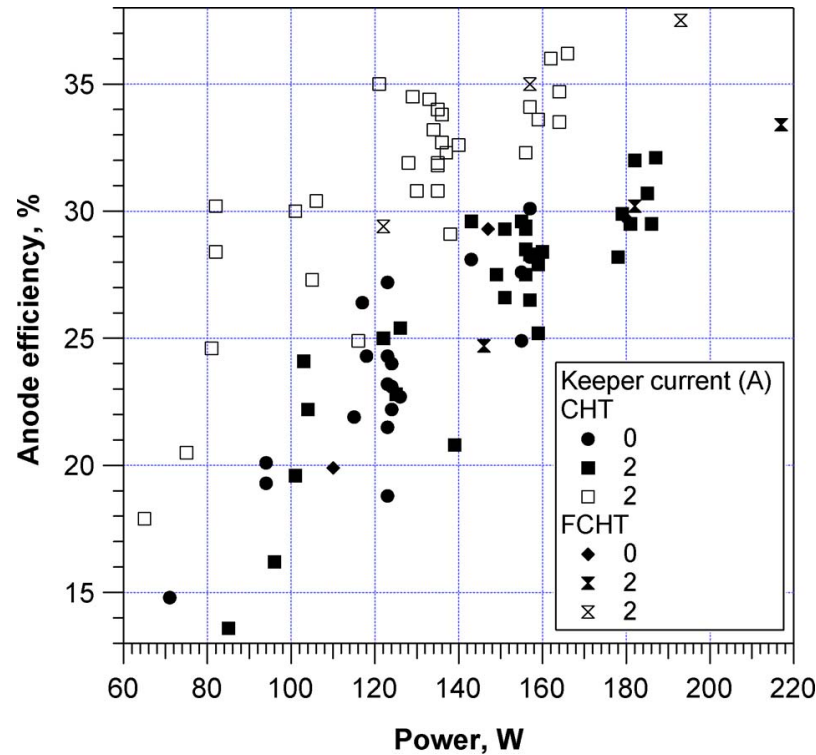

Fig. 6. Anode efficiency, excluding magnet power. CHT: 150-300 V, $0.28-0.40 \mathrm{mg} / \mathrm{s}$. FCHT: $200-300 \mathrm{~V}, 0.40 \mathrm{mg} / \mathrm{s}$. Filled symbols include keeper power in calculation of efficiency; open symbols do not.

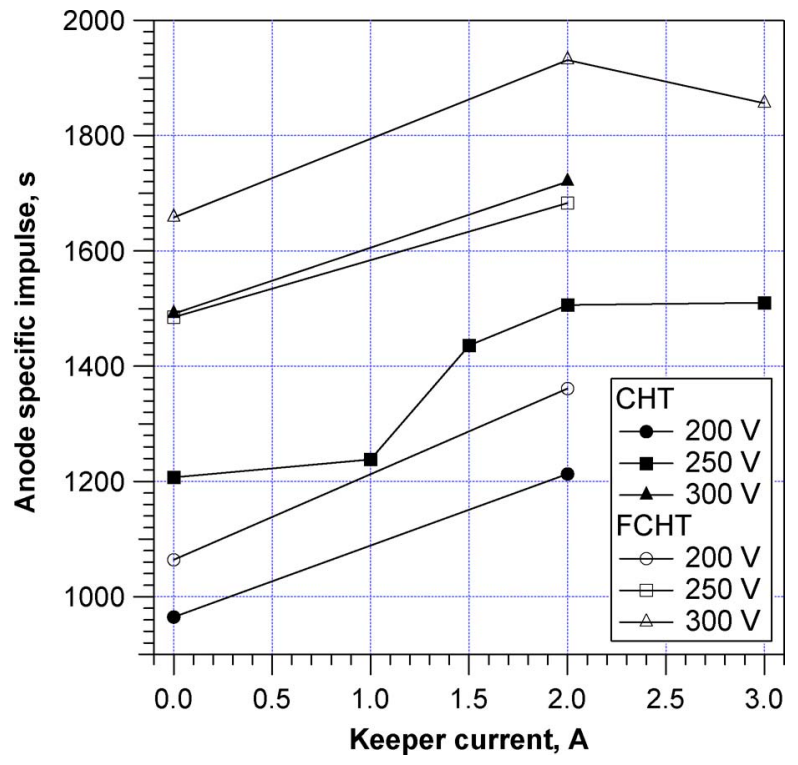

Fig. 7. Anode specific impulse at $0.40 \mathrm{mg} / \mathrm{s}$.

Fig. 8 shows that the mass utilization (ratio of beam current to anode mass flow rate expressed as an equivalent current assuming $100 \%$ single ionization) and current utilization (ratio of beam current to discharge current) efficiencies for both thrusters were weakly dependent on keeper current and discharge voltage and that mass utilization efficiencies were above $100 \%$. Mass utilization efficiencies were approximately $20 \%$ higher for the FCHT, but current utilizations were similar for both thrusters due to the roughly $20 \%$ larger discharge current of the FCHT. Reference [33] reported similar mass utilization efficiencies for a 2.6-cm-diameter CHT and presented evidence indicating that ingestion of cathode flow was not the cause. In this paper, assuming spherical expansion of the cathode flow from the keeper aperture results in an estimated neutral density at the thruster exit plane of about ten times the vacuum chamber background,

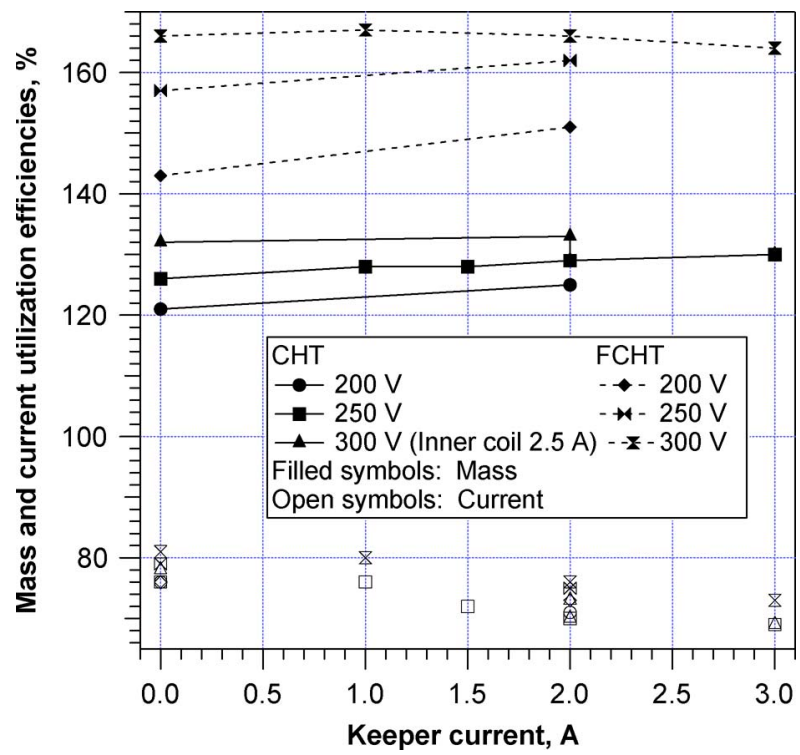

Fig. 8. Mass and current utilization efficiencies at $0.40 \mathrm{mg} / \mathrm{s}$.

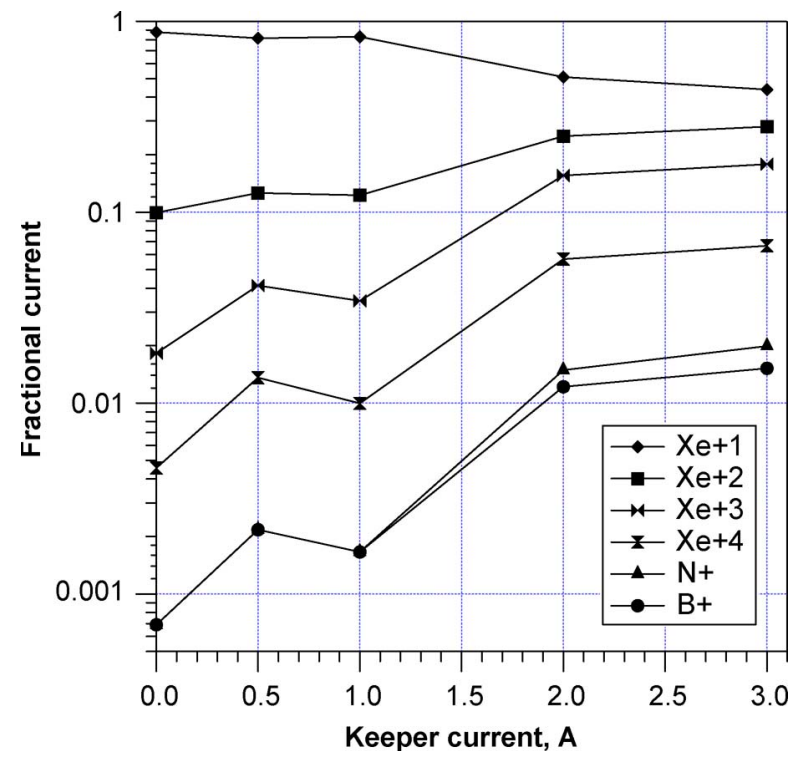

Fig. 9. CHT xenon charge state and erosion products at 50-cm radius, $250 \mathrm{~V}$, $0.40 \mathrm{mg} / \mathrm{s}, 40^{\circ}$ off centerline, and $223-\mathrm{V}$ energy-to-charge ratio.

leading to a propellant ingestion rate that is approximately $1 \%$ of the anode flow rate.

An explanation for high mass utilization in the CHT is provided by the data in Figs. 9 and 10, which show significant populations of multiply charged species at close to the primary ion energy. Reference [34] suggests that, due to the equipotentiality of magnetic field surfaces, ions borne in the near-axis region remain at low energy and are trapped by an ambipolar potential hill that develops in the cylindrical portion due to focusing of fast ions. The increased residence time (relative to conventional annular thrusters) allows the formation of higher charge states. This mechanism is supported by the data in Fig. 11, which show that the fraction of multiply charged ions increased with decreasing energy-to-charge ratio. Reference [34] also suggests that the multicharged ions could erode the central ceramic piece, and indeed, Fig. 9 shows that the quantity 


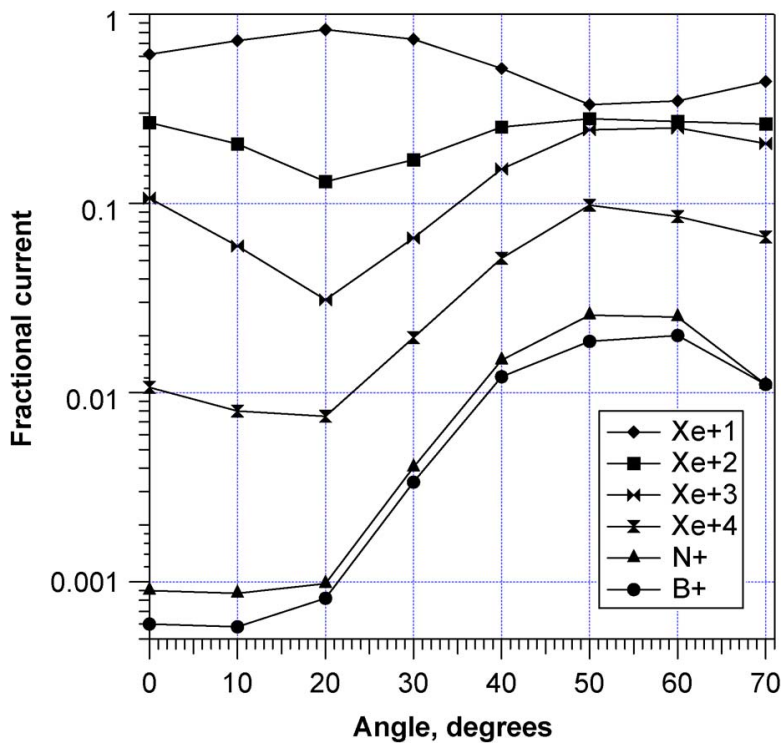

Fig. 10. CHT xenon charge state and erosion products at 50-cm radius, 2-A keeper current, $250 \mathrm{~V}, 0.40 \mathrm{mg} / \mathrm{s}$, and 223-V energy-to-charge ratio.

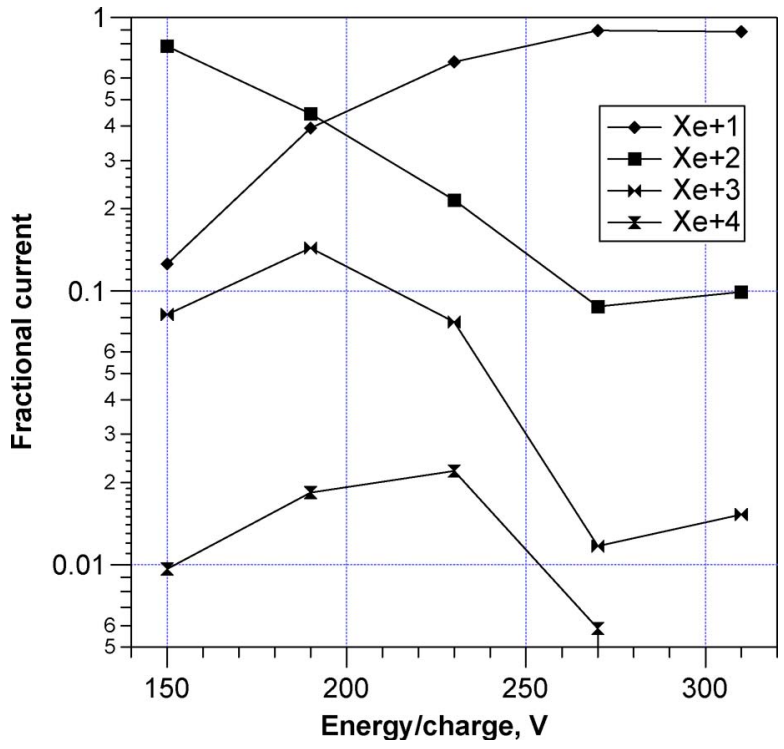

Fig. 11. CHT xenon charge state at 50-cm radius, 2-A keeper current, $250 \mathrm{~V}$, $0.40 \mathrm{mg} / \mathrm{s}$, and $30^{\circ}$ off centerline.

of $\mathrm{B}^{+}$and $\mathrm{N}^{+}$(from the $\mathrm{BN}$ ceramic) in the plume scaled with that of the multicharged Xe. Furthermore, the qualitative similarity between the angular distributions of $\mathrm{B}^{+}, \mathrm{N}^{+}$, and multicharged Xe (Fig. 10) suggests that they originate from a similar region. The data in Fig. 8 suggest that the number of multiply charged ions is greater in the FCHT, which could account for its larger specific impulse.

Note that, with the same thruster parameters, the keeper current increases the discharge current. This result demonstrates that, in steady-state operation of a thruster with a given geometry, the thruster discharge current is uniquely determined not only by the standard operating parameters such as the discharge voltage, gas flow rate, and magnetic field but also by the electron supply from the cathode [23]. The results shown in Figs. 8 and 9 may provide insight into this interesting result. Increasing the keeper current increases the quantity of multiply charged ions but reduces the fraction of single charged ions
(Fig. 9). As a result, the keeper current has a very mild influence on beam current (mass utilization, Fig. 8). Because the current utilization drops slightly with increasing keeper current, the increase of the discharge current with the keeper current is mostly due to increased electron mobility to the anode. A much larger effect on discharge current was observed by changing the CHT to the FCHT configuration (Fig. 8). However, the FCHT current utilization is about the same as the CHT. This result may imply that the production of multiply charged ions is responsible for the observed increase of the discharge current in the FCHT.

\section{CONCLUSION}

With its larger volume-to-surface-area ratio and simpler magnetic circuit, the CHT may possess advantages over conventional annular designs when scaling to low power. The CHT is known to produce a highly ionized plasma flow with mass utilization efficiency greater than $100 \%$. In this paper, we have demonstrated that unusually high mass utilization is due to multicharged ions formed in the thruster discharge. The presence of multicharged ions was found to be correlated with that of channel erosion products. Finally, we also verified that the effect of running a keeper discharge in addition to the anode discharge, previously reported for the CHT, exists also for a modified geometry (FCHT) for which the inner wall ends flush with the anode. FCHT efficiency was similar to that of the CHT, but specific impulse was higher, possibly due to the increased presence of multicharged ions. It would be interesting to investigate CHT operation on a gas that is more difficult to ionize (e.g., $\mathrm{Kr}$ ) to observe the effect of (presumably) reduced multicharged ion production.

\section{ACKNOWLEDGMENT}

The authors would like to thank Dr. T. Graves for his valuable assistance in the laboratory and also Dr. A. Smirnov for the helpful discussions.

\section{REFERENCES}

[1] J. D. Rendleman, "Why responsive space?" presented at the AIAA Space Conf. Expo., Pasadena, CA, Sep. 14-17, 2009, AIAA 2009-6652.

[2] J. M. Sankovic, J. A. Hamley, and T. W. Haag, "Performance evaluation of the Russian SPT-100 thruster at NASA LeRC," presented at the 23rd Int. Electric Propulsion Conf., Seattle, WA, Sep. 1993, IEPC 93-094.

[3] C. E. Garner, J. R. Brophy, J. E. Polk, S. Semenkin, V. Garkusha, S. Tverdokhlebov, and C. Marrese, "Experimental evaluation of Russian anode layer thrusters," presented at the 30th Joint Propulsion Conf., Indianapolis, IN, Jun. 27-29, 1994, AIAA 94-3010.

[4] M. B. Belikov, O. A. Gorshkov, R. N. Rizakhanov, and A. A. Shagayda, "Hall-type low and mean power thrusters output parameters," presented at the 35th Joint Propulsion Conf., Los Angeles, CA, Jun. 20-24, 1999, AIAA 99-2571.

[5] M. Lyszyk, E. Klinger, O. Secheresse, J. P. Bugeat, D. Valentian, A. Cadiou, T. Beltan, and C. Gelas, "Qualification status of the PPS1350 plasma thruster," presented at the 35th Joint Propulsion Conf., Los Angeles, CA, Jun. 20-24, 1999, AIAA 99-2278.

[6] D. King, D. Tilley, R. Aadland, K. Nottingham, R. Smith, C. Roberts, V. Hruby, B. Pote, and J. Monheiser, "Development of the BPT family of U.S.-designed hall current thrusters for commercial LEO and GEO applications," presented at the 34th Joint Propulsion Conf., Cleveland, OH, Jul. 12-15, 1998, AIAA 98-3338.

[7] V. Khayms and M. Martinez-Sanchez, "Design of a miniaturized hall thruster for microsatellites," presented at the 32nd Joint Propulsion Conf., Lake Buena Vista, FL, Jul. 1-3, 1996, AIAA 96-3291. 
[8] V. Hruby, J. Monheiser, B. Pote, P. Rostler, J. Kolencik, and C. Freeman, "Development of low power hall thrusters," presented at the 30th Plasmadynamics Lasers Conf., Norfolk, VA, Jun. 28-Jul. 1, 1999, AIAA 99-3534.

[9] N. Z. Warner and M. Martinez-Sanchez, "Design and preliminary testing of a miniaturized TAL hall thruster," presented at the 42nd Joint Propulsion Conf., Sacramento, CA, Jul. 9-12, 2006, AIAA 2006-4994.

[10] F. Battista, E. DeMarco, T. Misuri, and M. Andrenucci, "A review of the hall thruster scaling methodology," presented at the 30th Int. Electric Propulsion Conf., Florence, Italy, Sep. 17-20, 2007, IEPC 2007-313.

[11] M. Belikov, O. Gorshkov, E. Dyshlyuk, A. Lovtzov, and A. Shagayda, "Development of low-power hall thruster with lifetime up to 3000 hours," presented at the 30th Int. Electric Propulsion Conf., Florence, Italy, Sep. 17-20, 2007, IEPC 2007-129.

[12] E. Ahedo and J. Gallardo, "Scaling down hall thrusters," presented at the 28th Int. Electric Propulsion Conf., Toulouse, France, Mar. 17-21, 2003, IEPC 2003-104

[13] M. Belikov, O. Gorshkov, V. Muravlev, R. Rizakhanov, A. Shagayda, and A. Shnirev, "High-performance low power hall thruster," presented at the 37th Joint Propulsion Conf., Salt Lake City, UT, Jul. 8-11, 2001, AIAA 2001-3780.

[14] M. Belikov, O. Gorshkov, R. Rizakhanov, A. Shagayda, and S. Khartov, "Hall-type low- and mean-power thrusters output parameters," presented at the 35th Joint Propulsion Conf., Los Angeles, CA, Jun. 20-24, 1999, AIAA 99-2571.

[15] A. Loyan and T. Maksymenko, "Performance investigation of SPT-20M low power hall effect thruster," presented at the 30th Int. Electric Propulsion Conf., Florence, Italy, Sep. 17-20, 2007, IEPC 2007-100.

[16] Y. Raitses, N. J. Fisch, K. M. Ertmer, and C. A. Burlingame, "A study of cylindrical hall thruster for low power space applications," presented at the 36th Joint Propulsion Conf., Huntsville, AL, Jul. 2000, AIAA 2000-3421.

[17] Y. Raitses and N. J. Fisch, "Parametric investigations of a nonconventional hall thruster," Phys. Plasmas, vol. 8, no. 5, pp. 2579-2586, May 2001

[18] A. Smirnov, Y. Raitses, and N. J. Fisch, "Plasma measurements in a $100 \mathrm{~W}$ cylindrical hall thruster," J. Appl. Phys., vol. 95, no. 5, pp. 2283-2292, Mar. 2004.

[19] H. R. Kaufman, R. S. Robinson, and R. I. Seddon, "End-hall ion source," J. Vac. Sci. Technol. A, Vac. Surf. Films, vol. 5, no. 4, pp. 2081-2084, Jul. 1987.

[20] A. Smirnov, Y. Raitses, and N. J. Fisch, "The effect of magnetic field on the performance of low-power cylindrical hall thrusters," presented at the 29th Int. Electric Propulsion Conf., Princeton, NJ, 2005, IEPC-2005-099.

[21] A. Smirnov, Y. Raitses, and N. Fisch, "Enhanced ionization in the cylindrical hall thruster," J. Appl. Phys., vol. 94, no. 2, pp. 852-857, Jul. 2003.

[22] K. A. Polzin, T. E. Markusic, B. J. Stanojev, A. Dehoyos, Y. Raitses, A. Smirnov, and N. J. Fisch, "Performance of a low-power cylindrical hall thruster," J. Propuls. Power, vol. 23, no. 4, pp. 886-888, Jul./Aug. 2007.

[23] Y. Raitses, A. Smirnov, and N. Fisch, "Enhanced performance of cylindrical hall thrusters," Appl. Phys. Lett., vol. 90, no. 22, p. 221502 , May 2007.

[24] Y. Raitses and N. J. Fisch, "Cylindrical geometry hall thruster," USA, Patent No.: 6448721 B2, Sep. 10, 2002.

[25] A. Shirasaki and H. Tahara, "Operational characteristics and plasma measurements in cylindrical hall thrusters," J. Appl. Phys., vol. 101, no. 7, p. 073307, Apr. 2007.

[26] A. Smirnov, Y. Raitses, and N. Fisch, "Parametric investigation of miniaturized cylindrical and annular hall thrusters," J. Appl. Phys., vol. 92, no. 10, pp. 5673-5679, Nov. 2002.

[27] K. D. Diamant, J. E. Brandenburg, R. B. Cohen, and J. F. Kline, "Performance measurements of a water fed microwave electrothermal thruster," presented at the 37th Joint Propulsion Conf., Salt Lake, UT, Jul. 8-11, 2001, AIAA 2001-3900.

[28] J. E. Pollard and K. D. Diamant, "Hall thruster plume shield wake structure," presented at the 39th Joint Propulsion Conf., Huntsville, AL, Jul. 20-23, 2003, AIAA 2003-5018.

[29] J. E. Pollard, K. D. Diamant, V. Khayms, L. Werthman, D. Q. King, and K. H. de Grys, "Ion flux, energy, and charge-state measurements for the BPT-4000 hall thruster," presented at the 37th Joint Propulsion Conf., Salt Lake, UT, Jul. 8-11, 2001, AIAA 2001-3351.

[30] M. Mandell and I. Katz, "Theory of hollow cathode operation in spot and plume modes," presented at the 30th Joint Propulsion Conf., Indianapolis, IN, Jun. 27-29, 1994, AIAA 94-3134.

[31] M. Domonkos, M. Patterson, and A. Gallimore, "Low-current, xenon orificed hollow cathode performance for in-space applications," J. Propuls. Power, vol. 19, no. 3, pp. 438-443, May/Jun. 2003.
[32] E. Granstedt, Y. Raitses, and N. J. Fisch, "Cathode effects in cylindrical hall thrusters," J. Appl. Phys., vol. 104, no. 10, p. 103302, Nov. 2008.

[33] Y. Raitses, A. Smirnov, E. Granstedt, and N. J. Fisch, "Optimization of cylindrical hall thrusters," presented at the 43rd Joint Propulsion Conf., Cincinnati, OH, Jul. 8-11, 2007, AIAA 2007-5204.

[34] A. Smirnov, Y. Raitses, and N. J. Fisch, "Electron transport and ion acceleration in a low-power cylindrical hall thruster," presented at the 40th Joint Propulsion Conf., Fort Lauderdale, FL, Jul. 11-14, 2004, AIAA 2004-4103.

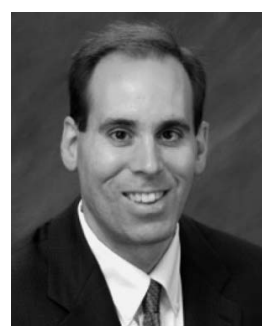

Kevin D. Diamant received the Ph.D. degree in mechanical and aerospace engineering from Princeton University, Princeton, NJ, in 1996.

$\mathrm{He}$ was with the Ion Propulsion Products Department, Hughes Electron Dynamics Division, as a Technical Staff Member from 1996 to 1998 and as a Staff Physicist from 1998 to 2000. He is currently a Research Scientist with the Propulsion Science Department, The Aerospace Corporation, El Segundo, CA. His research concerns electric propulsion for spacecraft.

Dr. Diamant is an AIAA Senior Member

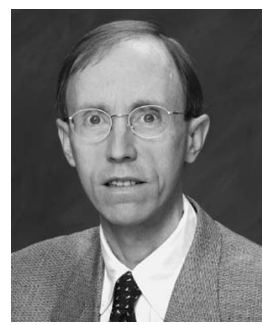

James E. Pollard received the Ph.D. degree in chemistry from the University of California, Berkeley, in 1982

$\mathrm{He}$ is currently a Senior Scientist with the Propulsion Science Department, The Aerospace Corporation, El Segundo, CA. His research concerns spacecraft propulsion and power.

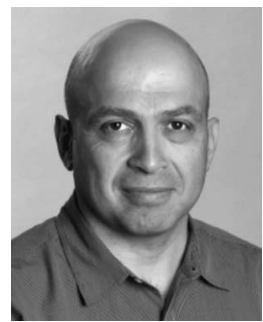

Yevgeny Raitses received the Ph.D. degree from the Technion-Israel Institute of Technology, Haifa, Israel.

He has previously held research positions with the Propulsion Physics Laboratory, Soreq NRC, Yavne, Israel. Since 1998, he has been with Princeton Plasma Physics Laboratory, Princeton University, Princeton, NJ, where he is currently leading research on plasma thrusters and related plasma technologies. His current research is focused on plasma-wall interactions in gas discharges, physics and applications of low-temperature magnetized plasmas, and plasma diagnostics.

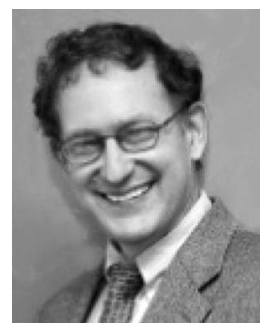

Nathaniel J. Fisch received the B.S., M.S., and $\mathrm{Ph} . \mathrm{D}$. degrees in electrical engineering and computer science from the Massachusetts Institute of Technology, Cambridge, where he was an MIT National Scholar, in 1972, 1975, and 1978, respectively.

$\mathrm{He}$ is currently a Professor of astrophysical sciences and the Director of the Program in Plasma Physics with Princeton University, Princeton, NJ. He is also an Associate Director for Academic Affairs and Head of the Hall Thruster Laboratory at the Princeton Plasma Physics Laboratory. At Princeton University, he is also an Associated Faculty with the Department of Mechanical and Aerospace Engineering. He is best known for predicting new ways to drive electric current in hot magnetized plasma by means of electromagnetic waves. In addition to plasma thrusters and related plasma devices, his current research interests include plasma-based methods of generating extreme laser intensities and fusion concepts employing magnetically or inertially confined plasma.

Prof. Fisch is a Fellow of the American Physical Society and the NASA Institute for Advanced Concepts. In 1998, he was the Chair of the Division of Plasma Physics of the American Physical Society. He received a Guggenheim Fellowship in 1985. He also received the American Physical Society Award for Excellence in Plasma Physics in 1992, the Department of Energy Bronze Medal for Outstanding Mentor in 2002, the Ernest Orlando Lawrence Award in 2004, and the 2005 James Clerk Maxwell Prize of the American Physical Society. 